\title{
ELLIPSIS AS A MARKER OF INTERACTION IN SPOKEN DISCOURSE
}

\author{
JONATHAN R. WHITE \\ Högskolan Dalarna, Sweden \\ jwh@du.se
}

\begin{abstract}
In this article, we discuss strategies for interaction in spoken discourse, focusing on ellipsis phenomena in English. The data comes from the VOICE corpus of English as a Lingua Franca, and we analyse education data in the form of seminar and workshop discussions, working group meetings, interviews and conversations. The functions ellipsis carries in the data are Intersubjectivity, where participants develop and maintain an understanding in discourse; Continuers, which are examples of back channel support; Correction, both self- and other-initiated; Repetition; and Comments, which are similar to Continuers but do not have a back channel support function. We see that the first of these, Intersubjectivity, is by far the most popular, followed by Repetitions and Comments. These results are explained as consequences of the nature of the texts themselves, as some are discussions of presentations and so can be expected to contain many Repetitions, for example. The speech event is also an important factor, as events with asymmetrical power relations like interviews do not contain so many Continuers. Our clear conclusion is that the use of ellipsis is a strong marker of interaction in spoken discourse.
\end{abstract}

Keywords: interaction, ellipsis, oral language, corpus

\section{Introduction}

The focus in this article is on the role of ellipsis in oral discourse. Specifically, we wish to demonstrate that ellipsis is a marker of oral interaction, and is an effective economy strategy in pragmatic communication. The focus is on learner data, as this study is part of a larger one to compare learner with native speaker data regarding language economy strategies. In an earlier study, White (2013) has argued that many of the markers of interaction discussed in the literature can be found in ellipsis contexts in his own corpus of learner data in text chatlogs.

The article reports our analysis of transcripts from the VOICE corpus of English as a Lingua Franca (VOICE, 2011). This is a corpus of learner English, as discussed in more detail in the Methodology section below. The most common strategy we find in the VOICE data is Intersubjectivity, where speakers develop understandings on a particular strand of discourse. The repetition of previous material and comments also frequently occur, along with back channel support markers.

The presentation of the results begins by discussing ellipsis and interaction, and the pragmatic role of ellipsis. White's work on ellipsis in text chatlogs rounds off this first 
part. Then, we present the data we will analyse in more detail. Different types of spoken data have been analysed, and the results of the analysis will be presented in successive sections, divided according to discourse type, and finally compared.

\section{Interaction and ellipsis}

\subsection{Ellipsis}

Ellipsis in the generative syntax literature (for example, Lobeck, 1995; Merchant, 2001, 2004; van Craenenbroeck, 2010) standardly means ellipsis with a syntactic context of the kind illustrated in (1):

(1) a. The cat chased the dog, and the rabbit did too.

b. Q: Where did you see him?

A: Over there.

The ellipsis here is considered syntactic because the Verb Phrase from the first conjunct in (1a), chased the dog, lets us recover the meaning of the second as the rabbit chased the dog too; and for (1b), the full question allows us to interpret the answer as I saw him over there. Merchant $(2001,2004)$ even proposes a syntactic derivation of (2) below, uttered on seeing a friend:

Hi there, nice to see you.

There is no similar syntactic context in (2), since it is the start of a conversation, but we easily understand it to be the equivalent of hi there, it is nice to see you.

The derivation of the answer in (1b) proceeds as follows for Merchant (2001). We first generate a full sentential answer, I saw him over there, and the part that is to remain after ellipsis, over there, is moved to the front of the sentence:

$$
\text { [I saw him over there] }=>\text { [over there [I saw him]] }
$$

Then, we delete I saw him, leaving the bare phrase behind ${ }^{1}$.

\footnotetext{
${ }^{1}$ Some evidence for this movement analysis comes from the fact that ellipsis is sensitive to movement islands - islands are structures that do not allow us to question material internal to them. Thus, we cannot leave a phrase behind after ellipsis that starts off within a syntactic island, for example a Noun Phrase island (Merchant, 2004: 688):
}

(i) Q: Did Abby vote for a Green Party candidate?

A1: *No, Reform Party

A2: No, she voted for a Reform Party candidate

To allow an answer like A1, we would need to move the modifier of a noun. So we would have to start from Abby voted for a Reform Party candidate, and move the noun modifier 
Stainton (2006) points out examples where it is not reasonable to argue for a syntactic input to ellipsis. For example, he describes the situation where a father is worried that his daughter will spill her drink (Stainton, 2006: 5). In that situation, he may utter the phrase both hands, meaning that she should use both hands to hold the cup. Stainton argues that there is no obvious suitable full sentential input to ellipsis which could be generated here. Instead, he proposes that the surface structure contains just the simple phrase, and that for the hearer the pragmatic component of grammar then supplies what is needed to decode a proposition. Merchant (2007) accepts Stainton's arguments, and proposes as a result that we can identify two types of ellipsis, syntactic and semantic. Semantic here really refers to ellipsis with a pragmatic context. Thus, in the father-daughter example, the daughter probably remembers that he has warned her before, and therefore can pragmatically interpret the bare phrase as you must use both hands to hold the cup.

After this very brief introduction to the phenomenon of ellipsis, let us move on now to interaction in spoken language.

\subsection{Interaction in spoken language}

What exactly spoken language is has been the subject of much debate. Beginning with classic work by Biber $(1986,1988)$ on the differences between spoken and written language, the debate has extended to include differences between oral and literate language (Holly, 1995). There is no simple divide between spoken and written language, as both can be more or less oral or literate. Thus, a conversation between friends differs markedly from a lecture or speech, but both are spoken; while textchat often differs from a novel even though both are written. As Scollon and Scollon (1995) remark, this is complicated still further by the multi-modality and multi-sensory nature of communication. Thus, textchat is on the face of it written, but is very oral in nature, and printed advertisements are multi-modal. Holly (1995: 346-347) summarizes features that can mark an oral language, and notes that ellipsis is one of those markers.

Interaction has received much attention in literature on second language acquisition and language learning, particularly computer-mediated language learning, over recent years. Discussing the speech acts that demonstrate a competence to interact, Chun (1994) takes up the following, based on work by Kramsch (1983): opening and closing conversations; constructing and expanding on topics; taking turns; capturing attention;

(ii) [Abby voted for a Reform party candidate] $=>$ *[Reform Party [Abby voted for a candidate]]

There is simple evidence that this sort of process is not possible in English from the following:

*Which did you read book?

In (iii), we are trying to move just the wh-word which, leaving the noun book behind, which is ungrammatical (see Ross, 1967 and Corver, 1990). So, Merchant argues that, for the same reason why we cannot question a modifier of a noun in a wh-question, we also cannot leave a modifier behind after ellipsis. 
steering or avoiding topics; elaborating on ideas; requesting confirmation or clarification; apologizing; giving feedback; and creating, expressing, interpreting and negotiating meaning.

Darhower (2002) also suggests greetings/leave-taking, plus intersubjectivity, humor, sarcasm/insults and the use of the L1 as markers of interaction. Intersubjectivity here refers to sharing or negotiating an understanding on a strand of interaction. Thus, clearly understanding and developing a discussion on a particular topic constitutes an example of intersubjectivity, which covers many of the functions of Chun's and Kramsch's above like expanding on topics, steering topics, elaborating on ideas and the final one on creating, etc. meaning. Negotiating intersubjectivity is an important feature for Darhower, and so seeking clarification is one such strategy that can be used when understanding is threatened. Like Darhower, Fernández-García and Martínez Arbelaiz (2003) also mention the use of an L1, particularly for echoing or asking for an explanation of a term.

Peterson (2009) presents evidence that Japanese learners of English are engaged in collaborative interaction in textchats. The strategies they used were: requests for assistance, provision of assistance, continuers, off-task discussion, self-correction and other-initiated correction (Peterson, 2009: 305). Assistance is described as having a positive effect on interaction; and therefore the asking for and receiving of assistance is important. Continuers refer to back-channel support which encourages others to continue their interaction (Cogo and Dewey, 2012: 139-142 also discuss back channel support in non-native speaker discourse). Off-task discussions create a social framework for the group, and reduce any anxiety at being required to interact in a foreign language. Finally, corrections initiated by a user are also positive strategies for learning. As Peterson notes, such interactive strategies create a sense of social cohesion and help establish discourse communities. Cogo and Dewey (2012: 139) also argue that they have a rapport-building function.

Repetition is a strategy mentioned by a number of authors in the literature. For example, Cogo (2009: 260), Suvimiitty (2012: chapter 7) and Mauranen (2012: chapter 7) all discuss the role of repetition as a communicative strategy for non-native speakers in ELF contexts.

The strategies we focus on for our analysis will be presented and justified at the start of the Data analysis section. We will now turn to the pragmatic function of ellipsis.

\subsection{The pragmatic function of ellipsis}

Oh $(2005,2006)$ discusses what she calls zero anaphora, or situational ellipsis. By this, she means the omission of personal pronouns (mostly subjects) from contexts in which the omitted material may be recovered by the hearer. She argues that, far from being a deviant and random linguistic device, ellipsis has a clear interactional function. Oh (2005) notes two contexts in which such ellipsis is commonly used in her corpus. One is the situation where an elliptical turn is marked as the second instance of a particular proposition. Consider the following extract from Oh (2005: 274) which has been reduced to take away all information about pauses (the predicate that has had its subject deleted is marked in bold type): 
(4)

\author{
Ruth: [I h've one] due Thu:rsday \\ Mark: [( )] \\ Ruth: Have one due tihmorrow.toọ:.=
}

In the extract, which is preceded by another speaker saying that she had a paper due in on Wednesday, Ruth comments that she has one due in on Thursday. She then makes a new statement saying that she has a paper due tomorrow as well, but omitting the subject I. Because of the repetition of the same type of linguistic material, the interpretation of the subject is recoverable here.

The other type of ellipsis for Oh (2005) concerns examples where new comments are made. Take the following from Oh (2005: 288), again reduced from the original example:

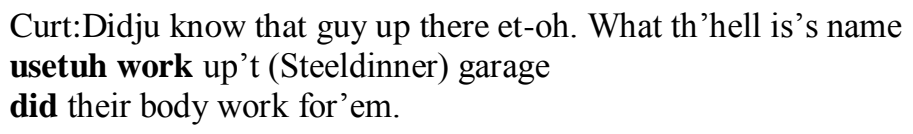

Here, Curt tries to remember the name of a man he is talking about, and provides two additional pieces of information about him, both using ellipsis of the subject. The listeners understand that these two comments have to refer to the man Curt is trying to describe - that is the most easily recoverable interpretation of these comments.

Oh (2006) adds additional categories to this classification. For example, there are examples of ellipsis coming after a parenthetical insert (Oh, 2006: 824):

$$
\begin{aligned}
& \text { M: I/I'll just I'll just start keeping track, start writing now } \\
& \text { W: yeah } \\
& \text { W: yeah } \\
& \text { M: s'I have't really gotten I've done reading } \\
& \text { M: haven't really'hh gotten down to it quite yet }
\end{aligned}
$$

The extract involves $\mathrm{M}$ and $\mathrm{W}$ talking about an assignment $\mathrm{M}$ is writing. $\mathrm{M}$ starts saying he has not gotten down to writing it, but interrupts the utterance with the parenthetical I've done reading. He then restarts the original utterance, but leaving the subject unsaid. The original utterance is close enough that $\mathrm{W}$ interprets M's last utterance as a restart of it.

Another strategy is to use ellipsis for marking topic cohesion (Oh, 2006: 830-831):

$$
\begin{aligned}
& \text { C: And it's a good forte to wear down there } \\
& \text { J: Right } \\
& \text { C: I bought a pair of Patty Woodards } \\
& \text { J: Yea::h } \\
& \text { C: An be very frank with you. Paid twenty-six dollars for them } \\
& \text { J: Yea:h= } \\
& \text { C: }=\text { Took them ho:me. Wore them one evening (.5) here }
\end{aligned}
$$


In this extract, $\mathrm{C}$ is talking about a bad quality pair of jeans she bought. She marks continuity in the discourse by subject ellipsis. Since J only interjects very minimal supportive utterances, $\mathrm{C}$ is virtually talking unopposed, and so the same subject can be supplied for all bold predicates.

The final strategy is for speakers to employ ellipsis to avoid making a referential choice (Oh, 2006: 835):

A: 'hhh so I w' $z$ out ' $n$ I ed sat in the car en reached over int'the glove compartment, en he came up tuh the door, en he said uhm 'hhh "Beatrice?" he said "Wouldju uh, mind if I would give you a call"

B: $\mathrm{Mm} \mathrm{hm}$

A: A:n I(hh) was so:: du(h)mbfounded yih(hh)kno(hhh)w //hhheh 'huhh! hhhhh

B: Oh::: Don' know what tuh SA:Y

A: I was so dumfoundid I really didn' know what tuh sa:y

Here A is telling B about meeting a prospective boyfriend. B's use of don' know could be interpreted as I don't know, or as a recasting of A's stating that she was dumbfounded. This referential choice can be hedged by the use of ellipsis, according to Oh.

Scott (2013) discusses the function of null arguments from a Relevance Theory perspective in diary entry discourse. She argues for three types of nulls (mostly subjects, but also objects). One is the informal use, where the null argument marks that the discourse is informal, and therefore that the speaker feels it is ok to relax the formal rules of English syntax and use null subjects/objects (White, 2011 makes the same point about the use of reduced and informal spellings in text chatlogs). The second type are null subjects/objects due to the limits of time and space in communication. Very often electronically-mediated communication is limited in this way. Thus, text messages are reduced linguistically to speed up writing, and similarly for textchat contributions; tweets are limited in size, etc. It is these restrictions that make null subjects/objects licit. Finally, we have ostensively vague arguments (like Oh's final category illustrated in (8)). In Scott's (2013: 78) example (46) from an ATM, OK. Got that, the programmer of the ATM does not want the machine to appear too human, and so the vague got that is a compromise from the too impersonal the machine got that.

We see that ellipsis carries many functions with it, and we would agree with Oh's and Scott's arguments that ellipsis is a valid and deliberate discourse strategy. Finally in this background section, let us consider the author's own evidence that ellipsis shares some of the above-mentioned features of interaction.

\subsection{Ellipsis as a marker of interaction}

White (2013) analyses textchat data from learners of English on an MA programme in English Linguistics. The data was divided into different functions, with the relevant part of each example marked in bold type. The data is taken from White (2013: 80-84). 
We have different types of examples that have been analysed as comments. Consider the first case below:

[8:49:10 PM] Student 4 says: In some coferences, seminars, meetings.. men tend to contribute more information and opinion, while women contribute more agreeing

Do $\mathrm{u}$ think so

[8:49:27 PM] Student 1 says: Absolutely right

Here we have a student asking a question about men's and women's language, and another student agreeing with the statement using the bare adjective phrase, absolutely right. We have as a part of our pragmatic knowledge the strategy that we comment on an utterance by using a bare phrase, and that comment relates to the previous discourse. Thus, (9) is really short for your contribution is absolutely right. This is an example of a Continuer in Peterson's (2009) classification since Student 1 is providing back channel support for Student 4.

Consider now a comment that is intended to develop another student's contribution:

[8:46:48 PM] Student 2 says: Women tend to speak faster than Man [8:46:59 PM] Student 1 says: Because women 's lang is rather different from men's. They use hedge, polite forms such as perhaps, maybe....

The example can be analysed as an example of Darhower's Intersubjectivity, in that one student is supplying additional information that adds to a previous student's point.

In the following example, we have a single case where students repeat a phrase to confirm that a previous contribution was on the right lines:

[9:55:06 PM] Student 4 says: men always base on the reality and women base on the

[9:55:22 PM] Student 6 says: feeling

[9:55:25 PM] Student 6 says: Student 4

[9:55:30 PM] Student 4 says: thanks Student 6

[9:55:41 PM] Student 7 says: on their own feelinng $\mathbf{s}$. It is right? Student $4 /$

[9:55:45 PM] Student 6 says: her own feeling abr life

[9:56:06 PM] Student 1 says: Yes, her own feelings

The phrase her own feelings is repeated by Students 7, 6 and 1, after Student 6 mentioned it before. This can be considered another example of Darhower's Intersubjectivity function, as details in the discourse are being confirmed. It is not real repetition as the phrase is not being repeated exactly, but being developed.

Next, we have a common category where students repeat specific words or phrases only in order to repair or correct previous contributions. Consider one representative example: 
[9:35:40 PM] Student 5 says: gender refer to social catagory

[9:36:03 PM] Student 1 says: Yes, Student 5

[9:36:18 PM] Student 5 says: some cases that's tue

[9:36:21 PM] Student 5 says: true

In this case, Student 5 repairs her own mistyping of true. This is clearly an example of the final category that is mentioned in Peterson's list, namely Repairs and Corrections. We see that students correct themselves and others, and this is seen as a positive strategy for learning.

We can see that a large variety of strategies have been proposed that establish and confirm interaction. Now, we present the data we are going to analyse for this article.

\section{Data and methodology}

As stated in the introduction, the analysis in the rest of the article involves data from the VOICE corpus, the Vienna-Oxford International Corpus of English (VOICE, 2011), a one million-word corpus of spoken English as a Lingua Franca. This data was chosen for a larger project of the author's which is a comparison of economy strategies in spoken and written oral language. The author's own corpus of data consisted of text chatlogs involving learners of English, so the VOICE corpus provides a natural spoken counterpart. ELF data is suitable for analysis of interaction, as much work recently by Cogo and Mauranen and others cited above has shown.

The VOICE corpus is divided into data from the following areas: education, leisure, professional business, professional organization, and professional research and science. There are a variety of speech event types within these areas, such as conversations, interviews and workshop discussions. We have concentrated on the speech events within the educational area, again to be closest in type to the author's own corpus. Academic discourse is interesting for study in itself, as learners negotiate different roles within the local community and in the academic community at large (Morita, 2004: 577). Local communities are vital for determining local interaction norms (as Mauranen, 2006: 127 and Pölzl and Seidlhofer, 2006 note for ELF communities; and Lave and Wenger, 1991 and Wenger, 1998 note for learning communities in general, their so-called communities of practice).

The speech events available within the education data are: conversations, interviews, seminar discussions, working group discussions and workshop discussions; and all of these have been analysed. The instances of ellipsis and their functions have been identified, and these will be presented and compared across speech event type in the following sections. Texts are given a code for the general area and speech event plus a number for the text. Thus, a seminar discussion in education will have a code starting EDsed. The markup conventions used in the corpus are described in the following link: http://www.univie.ac.at/voice/documents/VOICE_mark-up_conventions_v2-1.pdf. The 
number of examples of each function has been calculated, and will be presented in the form of tables.

\section{Data analysis}

Out of the strategies we noted above from Darhower (2002) and Peterson (2009), two were not found in the data. They are: Requests for Assistance, which have been analysed as Intersubjective; and Off-task Discussion (they do exist, but not in elliptical form). The Use of L1 strategy has been discounted, as we are specifically looking for data in English, and the speakers all have L1s other than English. There are cases of translation into English, and these have been analysed as examples of Intersubjectivity, as understanding is being promoted.

There were instances of the Greeting/Leave-taking and Apology strategies mentioned by Darhower (2002) and Chun (2004), respectively. However, these have been removed from the results, as we have chosen to focus on language that has been generated directly by users rather than applied as a formula. Thus, we are concentrating on the following functions: Intersubjectivity, Continuers and Correction. We also recognise Repetition as a function, following the work by Cogo (2009), Suvimiitty (2012) and Mauranen (2012) mentioned in the background. Repetition cannot be included under Intersubjectivity, in that the discourse is not being developed; rather something is being confirmed. Then, we are adding one of our own: Comment. We take Comments to be different from Continuers, in that Comments do not play the role of back channel support. We have chosen not to recognise as ellipsis examples where a speaker restarts a phrase s/he started in an earlier contribution.

We will now look at examples of each function, beginning with examples of Intersubjectivity.

\subsection{Intersubjectivity}

We will start the presentation of the Intersubjectivity function with examples of answers to questions. The first comes from the conversation marked EDcon4, and the second from EDcon496, and the parts with ellipsis we are focusing on are marked in bold type:

796S2: do you think so

797S1: <soft> yeah </soft> (.)

798S2: are you sure

799S1: not SURE but (.) i think so (.)

2S2: why are you STRESSing

3S3: <soft> yeah </soft>

4S1: cos cos i don't wanna be saying you know stupidities in front of a class 
In the first example, Speaker 2 has asked the yes-no question, are you sure, and Speaker 1 replies not sure. The syntactic context of the question clearly allows Speaker 1 to use this elliptical answer. In (14), we have an answer to a wh-question, and here it is a reason clause starting with $\cos$ which is the new information that needs to be given only. These are clear examples of Intersubjectivity, as answering a question develops the discourse, and negotiates an understanding between the participants.

There are also many examples of elliptical questions, starting with a repeated question from EDcon496:

128S1: $\langle 9\rangle\langle$ slow $>$ to address $</$ slow $\rangle\langle/ 9\rangle$ \{S1 takes notes on the laptop while speaking \} (3) a new (2) customer (2) segment (2) customer segment (2) <fast>

and what is it that you just said a minute ago </fast> what?

Here Speaker 1 asks what another speaker has said, and repeats just the wh-word, what. Next, we have a request for clarification from EDcon4:

23S1: $<3>$ i $</ 3>$ don't know because i skipped few questions. (.) i didn't participate actively @ (.)

24S2: okay (2) so erm [first name3] was not upset (.) [first name3] (.)

25S1: about what $($.

This time, Speaker 1 does not understand Speaker 2's comment about an individual not being upset, and uses the elliptical about what. These are also Intersubjective, because they are negotiating understanding. The questioners are unclear about something, and are asking for clarification. Such negotiations are the core of Intersubjectivity, for Darhower.

We also find similar examples of elliptical questions and answers in other speech events like interviews. (17) and (18) are from the same interview, EDint330, while (19) comes from EDint328:

451S1: you're very scholarly answers

452SS:@@@@@

453S2: ready?@@

531S1: so which language do you like better. (.)

532S2: <soft> english </soft>

533S1: english. and why@@

534S2: because i can express myself better in ENGlish.

363S1: and did you teach them english (.) er at home? (1) two two of you did you speak to them english?

364S2: yes $\langle 6\rangle$ we did $\langle/ 6\rangle$

365S1: $\langle 6\rangle$ to your $\langle/ 6\rangle$ children

366S3: $\langle 7\rangle$ when they $\langle/ 7\rangle$ were young at school? (.) we used to help them.

367S2: $\langle 7><$ soft $>$ yes we did $</$ soft $></ 7>$ 
These are very similar to the examples from conversations given above. We have the single-word question ready in (17); and the subordinate clause answer in (18) and the answer to a yes-no question involving complement ellipsis in (19). A follow-on question is exemplified below, from EDint331:

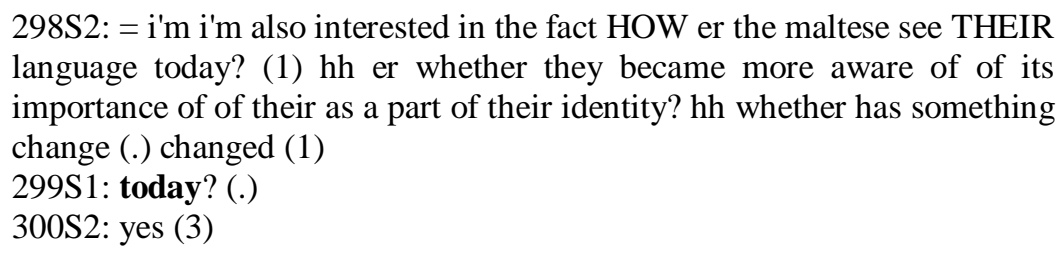

The temporal adverbial today is used to question when something has changed in Maltese society regarding their language. The following examples of answers can be found in workshop discussions. The first comes from EDwgd5, and the second from EDwgd305:

159S7: <1> do you have an $<$ un $>\mathrm{xx}</ \mathrm{un}>$ with what we did $</ 1>$ friday? (.) last friday? (.) 160S4: <2> n:ot with me </2>

404S2: $<8>$ would you give us $</ 8>$ (.) s:ome (.) kind of hint (.) when it's like (.) fifteen minutes to to $\langle$ un $>\mathrm{x}\langle 1\rangle \mathrm{xx}</ 1></$ un $>$

405S7: <1> yes $</ 1>$ (.) yeah i will i will (.) yeah? (.) okay (.) no further questions? (2) no questions on how? (2) \{S7 leaves again $\}$

We have an answer that gives additional information for the question in (21), and the complement ellipsis answer in (22). Again, the discourse is being developed or negotiated.

We also find a number of examples with translations coming in elliptical contexts, such as the following from the conversation, EDcon4:

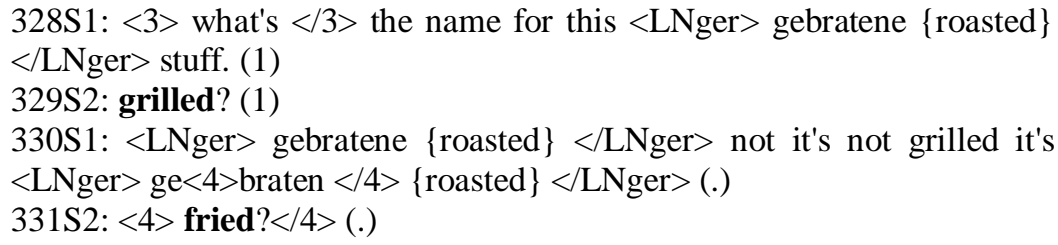

Here, Speaker 2 offers two translations of the German term gebratene. S/he does not use a full sentence, but just the appropriate lexical item. As mentioned above, we treat translations as Intersubjective, since they are supplying extra information to develop the discourse, and, in the case above, answer a direct question. We find examples of translations like the following from the seminar discussion, EDsed31: 
417S6: a:nd then $i$ have a german word this is called $<$ L1ger $>$ eitel $\{$ vain $\}$ $</$ L1 ger $>$ (.) $<7>$ i don't $</ 7>$ know the (.)

418S1: $\langle 7><$ soft $>\mathrm{mhm}</$ soft $></ 7>$

419S6: english word

420S1: e:rm (.)

421S18: vain

422S1: VAIN yeah that's right $<@>$ thanks. $</ @>$ @ $<8>$ @ $</ 8>$

Speaker 6 asks for the translation of eitel, and Speaker 18 gives vain, which Speaker 1 confirms. These translations clearly promote understanding of discourse, therefore we analyse them as Intersubjective.

Moving on, we have extra information given below in elliptical form from the interview, EDint331:

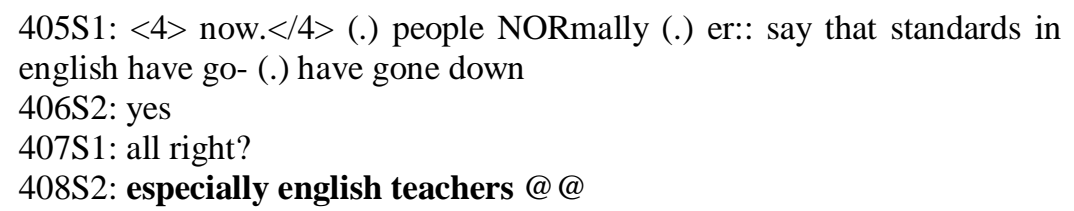

Speaker 1 is making a comment about standards in English, and Speaker 2 gives the extra information that this is especially the case among English teachers. There are examples of completion of information from working group discussions, like EDwgd5:

$$
\begin{aligned}
& \text { 3S1: and there are enlargement issues? } \\
& \text { 4SS: mhm (.) } \\
& \text { 5S1: well actually it is also er }= \\
& \text { 6S3: = for common (.) foreign }(.)<2>\text { security policy. }</ 2>
\end{aligned}
$$

Speaker 3 completes Speaker's 1 point about enlargement issues in the European Union. This additional information adds to understanding of an issue, which is why we analyse them as Intersubjective.

Finally in this section, we have a rare example of gapping from the interview, EDint328:

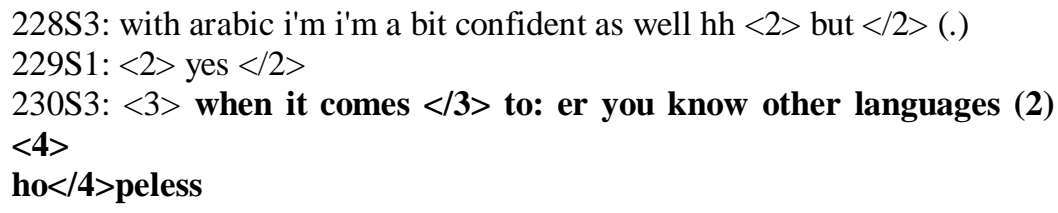

The gapping comes when Speaker 3 comments on her ability in speaking Arabic, and contrasts it with other languages. She means that she is hopeless with other languages, but the context of her comment on Arabic means that she does not need to give the full sentential utterance. This is similar to the previous cases, with additional information being added to promote better understanding. 
As we can see, there are a variety of structures from all the speech events that carry the Intersubjectivity function. Let us now move onto examples with the Continuer function.

\subsection{Continuers}

Firstly, we have a comment from the conversation, EDcon4:

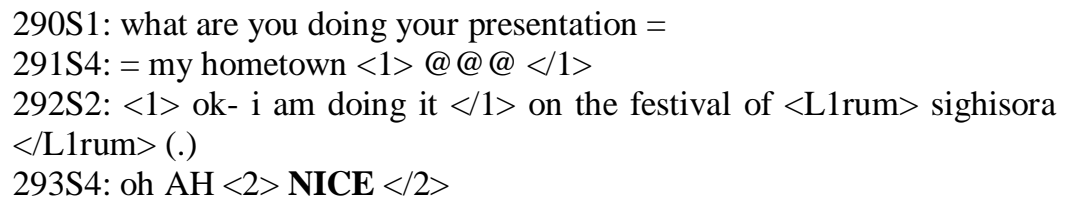

There are many examples of this type, with a simple adjectival comment like nice. A similar example of a comment involving a bare adjective is the following from the interview, EDint330:

4S1: i have one er questionnaire in english $\mathrm{s}-$ and $\mathrm{i}$ will $<2>$ just $</ 2>$ compare (.) you know (.)

5S3: $\langle 2>$ (good) for you $</ 2>$

6S2: okay (1)

Then, we have the comment from the seminar discussion, EDsed31:

95S9: (and i'm) twenty-six and i've been to austria many times before (1) and erm (1) i came to austria because i (.) <soft> er </soft> i've (.) very g(.) good experiences and i've met (.) many nice (.) people (.) in austria before (.) and er (.) one (.) big reason is because i like the mountains a lot. (.) and i just wanted to be closer (.) to <3> the alps. @ @ </3> 96SS: <3>@@@</3>@@(.)

97S1: <@>good reason</@>@@@@ hh

In this case, there is a nominal phrase good reason. They are all clear examples of Continuers, as they are functioning as back channel support. Such socially cohesive strategies are very important for promoting group unity, and therefore we might expect them to be very popular strategies (the actual situation will be made clear when we look at the frequencies in section 4.6). We will now move in to Corrections.

\subsection{Correction}

The next example is of a speaker correcting and completing information from the conversation, EDcon521: 


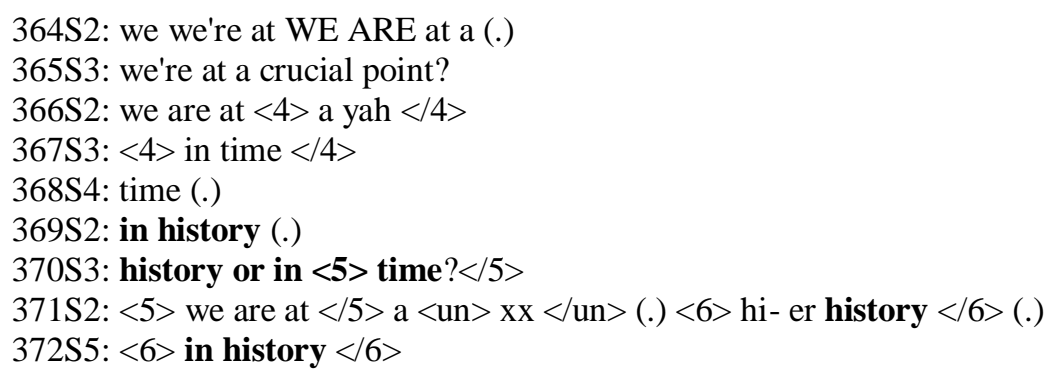

Speaker 3 starts with the utterance we're at a crucial point, and adds in time. Speaker 2 disagrees and corrects this with the elliptical in history, and Speaker 5 confirms this. As only the relevant information is necessary, only the prepositional phrases are required.

Corrected information is given in the following from the working group discussion, EDwgd5:

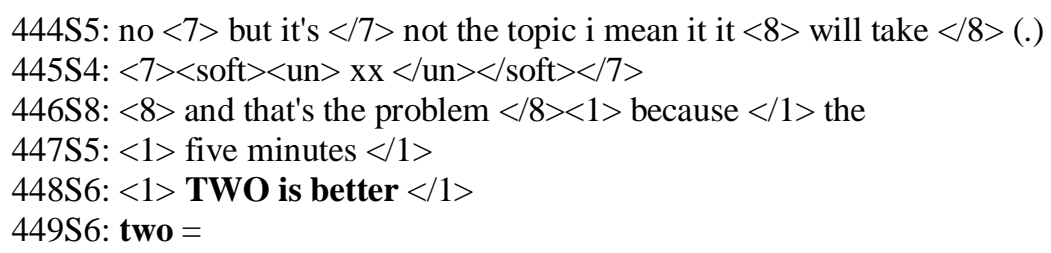

Speaker 5 suggests that their presentation will take five minutes, but Speaker 6 corrects that to two. S/he does not need to give a complete sentential utterance, but can simply correct the appropriate part.

Another example of correction comes from the workshop discussion, EDwsd242:

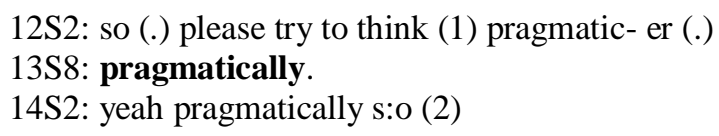

Speaker 2 uses the adjective pragmatic instead of the adverb pragmatically, and Speaker 8 corrects her. There were no examples of self-correction in this corpus (although many were found in Author's textchat corpus). Now, we will consider Repetitions.

\subsection{Repetition}

We have an example of repetition from the interview, EDint328:

262S1: = so its something very specific (.) er about which you can speak in english (.) for example movies (.) and the $\langle 6\rangle$ books $\langle/ 6\rangle$ (1) 63S2: $\langle 6\rangle$ the books $\langle/ 6\rangle$

264S2: so (.) so (.) shall we shall i write books? 
265S1: yes books and movies (1) it's more general than (.) than this one (15) $\{\mathrm{S} 2$

and $\mathrm{S} 3$ are filling out the questionnaire (15) $\}$

Speaker 2 asks whether she should write that she uses English most when reading books, and Speaker 1 repeats and expands that with the co-ordinated books and movies.

Next comes an example of repetition in (35) from the working group discussion, EDwgd5:

282S6: $<5>$ yeah d- let's do it $</ 5>$ this on (.) on wednesday yeah?

283S4: yeah =

284S3: = <soft $>$ wednesday $</$ soft $>$

The repetition of Wednesday acts as a confirmation that something will happen then.

In seminar discussions, we see examples of repetitions like the following from EDsed31:

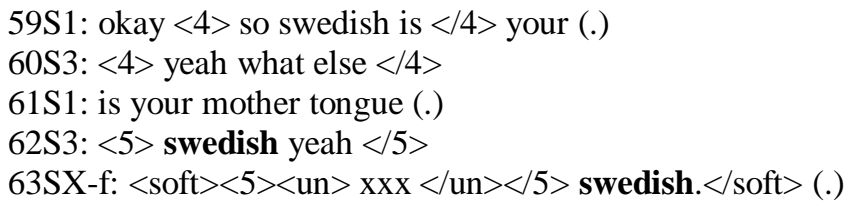

Speaker 1 asks Speaker 3 if Swedish is her mother tongue, and she confirms this, and another unknown female speaker also repeats the phrase Swedish.

There is an example of repetition and clarification from EDsed362:

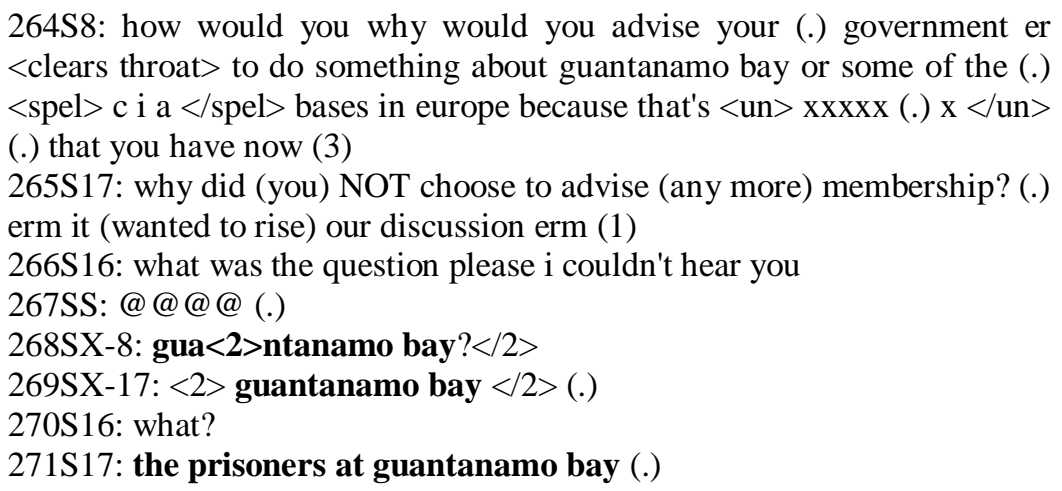

Speaker 8 asks a question about what to do about places like Guantanamo Bay, and Speaker 16 does not hear and asks for the question to be repeated. Speaker 8 repeats just the phrase Guantanamo Bay, as does Speaker 17.

There is the following example of repetition from the workshop discussion, EDwsd306: 
995SX-7: this is democratic then.

996SX-f: <soft> mhm </soft>

997SX-7: very democra $<$ 8 $>$ tic $</ 8>$

Speaker 7 comments that something is democratic, and repeats and expands on that with very democratic. The common theme for Repetitions is that they are used to confirm but crucially clarify discourse elements. Thus, they provide extra understanding on discourse. They are quite similar to the examples of Intersubjectivity in section 4.1 in this respect, but the repetitive aspect makes them different, and therefore we have chosen to give them their own label. The last set of examples comes from Comments.

\subsection{Comment}

There is a comment from the working group discussion, EDwgd241:

274S1: it's actually a bit dangerous $\mathrm{i}<3>$ think $\langle/ 3\rangle\langle 4\rangle$ if there $<$ un $>$ $\operatorname{xxxx}</$ un $></ 4>$

275S4: $\langle 3\rangle$ yeah $\langle/ 3\rangle\langle 4>$ it's a kind of $\langle/ 4>$ nationalism or something

like $\langle 5\rangle$ that $\langle/ 5\rangle$ (if it is) $\langle 6\rangle$ yeah (total) imperialism $\langle/ 6\rangle$

276S5: $<4>$ very dangerous $</ 4>$

Speaker 5 comments on imperialism, expanding on Speaker 1's comment earlier by saying very dangerous. This cannot be analysed as a Continuer, as the comment is not designed to be back channel support for Speaker 1 in his/her point, just to comment on the point being made. We find a similar comment from the workshop discussion, EDwsd9:

121S5: <1> you have </1> scenario number two

122S7: no.

123S5: number $\langle 2\rangle$ three $\langle/ 2\rangle$

124SS: $\langle 2\rangle @ @</ 2\rangle\langle 3\rangle @ @ @ @</ 3\rangle$

125S7: $\langle 3\rangle$ no. (.) n-n n-n n-n n-n $\langle/ 3\rangle\langle<@>$ impossible $</ @\rangle$

This is the standard type of comment with the bare adjective impossible.

Finally, we have the following example of complement ellipsis from EDwsd242:

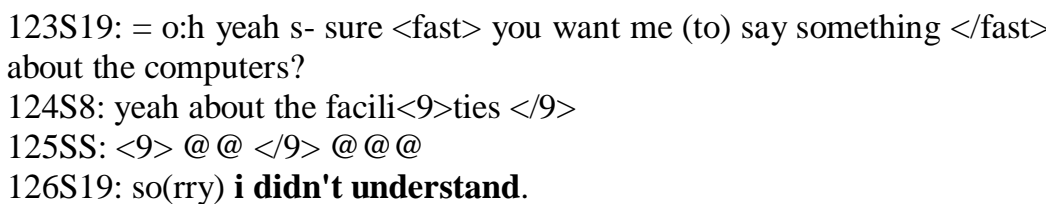

The complement of understand has been subject to ellipsis. 
These all comment on the discourse topic, but are different from Continuers. Finally, we will look at the frequencies at which these functions appear in the data, and comment on the tendencies that emerge.

\subsection{Frequencies in speech events}

We have seen that ellipsis carries many functions in the data. In the tables below, we summarise this information and present how many instances of each function there were in each speech event as a whole. The left-hand column in each table contains the reference numbers for the texts. We start with the functions appearing in conversations:

\begin{tabular}{|c|c|c|c|c|c|}
\hline Text\# & InterSubj & Continuers & Correction & Repetition & Comment \\
\hline 4 & 79 & 4 & 0 & 6 & 7 \\
\hline 250 & 42 & 7 & 0 & 8 & 12 \\
\hline 496 & 53 & 4 & 1 & 3 & 9 \\
\hline 521 & 53 & 14 & 0 & 15 & 18 \\
\hline $\begin{array}{c}\text { Total } \\
(\mathbf{3 3 5})\end{array}$ & $\mathbf{2 2 7}$ & $\mathbf{2 9}$ & $\mathbf{1}$ & $\mathbf{3 2}$ & $\mathbf{4 6}$ \\
$\mathbf{( 6 7 . 7 6 \% )}$ & $(\mathbf{8 . 6 6 \% )}$ & $\mathbf{( 0 . 3 0 \% )}$ & $\mathbf{( 9 . 5 5 \% )}$ & $\mathbf{( 1 3 . 7 3 \% )}$ \\
\hline
\end{tabular}

Table 1: Ellipsis in conversations

A trend we see in all speech events is that Intersubjectivity is by far the most common strategy. Comments come in ahead of Repetition and Continuers in conversations, while there is only one instance of Correction. This can be due to the fast nature of oral communication in conversations, as there is very little time to repair mistakes by oneself or others. Even in an education context, speakers do not repair mistakes they and others make so often.

Conversations have been described in the literature in different terms from more typical academic discourse like seminar discussions (Pölzl and Seidlhofer, 2006: 969). Academic discourse in general is seen as institutional in nature (Heritage, 2005) in that discourse behaviour of individuals can be explained as a consequence of the constraints of the academic genre, for example the power relationships between teachers and students. As Mauranen (2006: 128) notes, the primary goal of casual conversations is to socialise, which is very different from the goal of an academic seminar. In this regard, the lower percentage of Continuers can be considered surprising - plus that almost half of the instances come in the final text, EDcon521. That particular text is surprising, in that nearly half of the Repetitions come there too. In that text, the speakers were working on a presentation, and so there was much repetition of individual points, such as the following:

360S5: $<3>$ yeah $</ 3>$ le- let's write it down

361S2: you have a much better handwriting

362S3: @@@ @ okay(3)e:rm

363SX-f: nowadays (.)

364S2: we we're at WE ARE at a (.) 
365S3: we're at a crucial point?

366S2: we are at $\langle 4>$ a yah $</ 4>$

367S3: $<4>$ in time $</ 4>$

368S4: time (.)

369S2: in history (.)

370S3: history or in $\langle 5\rangle$ time? $</ 5\rangle$

371S2: $\langle 5\rangle$ we are at $\langle/ 5\rangle$ a $\langle$ un $>\mathrm{xx}\langle/$ un $\rangle$ (.) $\langle 6\rangle$ hi- er history $\langle/ 6\rangle$ (.)

372S5: $\langle 6\rangle$ in history $\langle/ 6\rangle$

373S2: history is good (2)

374S4: what we're at a crucial time in history or

375S2: <soft $\rangle$ at a crucial POINT in $\langle 7\rangle$ history $\langle/ 7\rangle\langle/$ soft $\rangle$

376SX-f: $\langle 7\rangle<$ soft $><$ un $>$ xxx $</$ un $></$ soft $></ 7>$

377S4: point in history (6)

378S3: <slow $><$ reading_aloud $>$ point in

history? $</$ reading_aloud $></$ slow $>($.)

$\langle 8\rangle$ or $\langle/ 8\rangle$ in time $=$

There are many examples of ellipsis here with a particular point being discussed. The phrase in history is repeated many times. Also, there were many Continuers in this text, as speakers commented on each other's suggestions. Speaker 2's contribution in line 372 is an example of support for a particular wording, history is good.

Let us move on now to the interview data:

\begin{tabular}{|c|c|c|c|c|c|}
\hline Text\# & InterSubj & Continuers & Correction & Repetition & Comment \\
\hline 328 & 44 & 5 & 0 & 16 & 8 \\
\hline 330 & 48 & 5 & 0 & 9 & 9 \\
\hline 331 & 33 & 3 & 0 & 4 & 4 \\
\hline 604 & 10 & 3 & 0 & 2 & 1 \\
\hline 605 & 13 & 1 & 2 & 4 & 4 \\
\hline Total (/228) & $\mathbf{1 4 8}$ & $\mathbf{1 7}$ & $\mathbf{2}$ & $\mathbf{3 5}$ & $\mathbf{2 6}$ \\
& $\mathbf{( 6 4 . 9 1 \% )}$ & $\mathbf{( 7 . 4 6 \% )}$ & $\mathbf{( 0 . 8 8 \% )}$ & $\mathbf{( 1 5 . 3 5 \% )}$ & $(\mathbf{1 1 . 4 0 \% )}$ \\
\hline
\end{tabular}

Table 2: Ellipsis in interviews

Once again, Intersubjectivity is the most common strategy. This can also be considered an institutional genre, as there are expectations for how participants interact, i.e. the interviewer is in charge of directing the discourse. For interviews, though, Repetition comes in second place before Comments. There are many examples of Repetition in EDint328, as this is an interview where a couple are filling in a form about language attitudes in Malta. Therefore, there is a lot of repetition about details in the form, such as the following:

23S1: and it would be useful to know what you did (.) e:r

24S3: okay $=$

25S1: = when you worked (1) 
26S3: hh okay e:rm (3)

27S1: e:r self-employed? $<8>$ you have $</ 8>$ self- self-employed (1)

28S3: $<8>$ self-employed yes $</ 8>$

In this example, one of the couple's profession before retirement is identified, and Speaker 3 repeats self-employed. In the last two interviews, EDint604 and EDint605, there is an unusually low amount of Intersubjectivity. This can be simply explained by the fact that the texts are very short, at 229 and 276 lines, respectively. EDint330 is the longest at over 1000 lines, but the other have around 750 each.

Now, we turn to working group discussions:

\begin{tabular}{|c|c|c|c|c|c|}
\hline Text\# & InterSubj & Continuers & Correction & Repetition & Comment \\
\hline 5 & 29 & 4 & 0 & 14 & 8 \\
\hline 6 & 21 & 0 & 0 & 7 & 3 \\
\hline 241 & 31 & 13 & 0 & 9 & 5 \\
\hline 305 & 38 & 18 & 0 & 15 & 8 \\
\hline 497 & 34 & 12 & 1 & 3 & 7 \\
\hline Total (/280) & $\mathbf{1 5 3}$ & $\mathbf{4 7}$ & $\mathbf{1}$ & $\mathbf{4 8}$ & $\mathbf{3 1}$ \\
& $\mathbf{( 5 4 . 6 4 \% )}$ & $\mathbf{( 1 6 . 7 9 \% )}$ & $\mathbf{( 0 . 3 6 \% )}$ & $\mathbf{( 1 7 . 1 4 \% )}$ & $\mathbf{( 1 1 . 0 7 \% )}$ \\
& & & & & \\
\hline
\end{tabular}

Table 3: Ellipsis in working group discussions

Intersubjectivity is still the most common strategy, but the percentage is decreasing. This is another institutional genre, where particular tasks for the group govern the discourse. Repetition and Continuers are almost equally common. There are very few Continuers in texts EDwgd5 and EDwgd6, most likely because they are the shortest discussions, at just over 700 lines each compared to over 1000 for the other three. The number of Repetitions varies much. There are many in EDwgd5 and EDwgd305 as speakers here are organising a presentation, and so many details are repeated, such as when the presentation will be. The example comes from EDwgd5:

$$
\begin{aligned}
& \text { 244S3: }<5>\text { when IS }</ 5>\text { our presentation? } \\
& \text { 245S6: }<6>\text { i think? }</ 6>\text { on friday. } \\
& \text { 246S5: }<6>\text { on friday. }</ 6> \\
& \text { 247S3: on friday? } \\
& \text { 248S5: }<7>\text { yeah. }</ 7> \\
& \text { 249SX }-1:<7><\text { soft }>\text { on friday? }</ \text { soft }></ 7>
\end{aligned}
$$

Next, we consider seminar discussion data:

\begin{tabular}{|c|c|c|c|c|c|}
\hline Text\# & InterSubj & Continuers & Correction & Repetition & Comment \\
\hline 31 & 83 & 10 & 2 & 36 & 11 \\
\hline 251 & 16 & 14 & 0 & 12 & 7 \\
\hline 301 & 12 & 12 & 0 & 11 & 0 \\
\hline 362 & 16 & 3 & 1 & 5 & 4 \\
\hline
\end{tabular}




\begin{tabular}{|c|c|c|c|c|c|}
\hline Text\# & InterSubj & Continuers & Correction & Repetition & Comment \\
\hline 363 & 18 & 19 & 4 & 10 & 1 \\
\hline 364 & 10 & 17 & 2 & 1 & 2 \\
\hline Total (/339) & $\mathbf{1 5 5}$ & $\mathbf{7 5}$ & $\mathbf{9}$ & $\mathbf{7 5}$ & $\mathbf{2 5}$ \\
& $\mathbf{( 4 5 . 7 2 \% )}$ & $\mathbf{( 2 2 . 1 2 \% )}$ & $\mathbf{( 2 . 6 5 \% )}$ & $\mathbf{( 2 2 . 1 2 \% )}$ & $\mathbf{( 7 . 3 7 \% )}$ \\
\hline
\end{tabular}

Table 4: Ellipsis in seminar discussions

Just as with the previous data, in seminar discussions Intersubjectivity is most common, with Repetition and Continuers coming behind. Text EDsed31 stands out with the most Intersubjectives, Repetitions and Comments. It is more than twice the length of the other texts, at 1700 lines compared to at most 700 for EDsed251. There is a lot of Repetition in the text, as students are introducing themselves, and details are repeated by the students, and also students are supposed to give their ideas about stereotypes of Austrians, and these are also repeated:

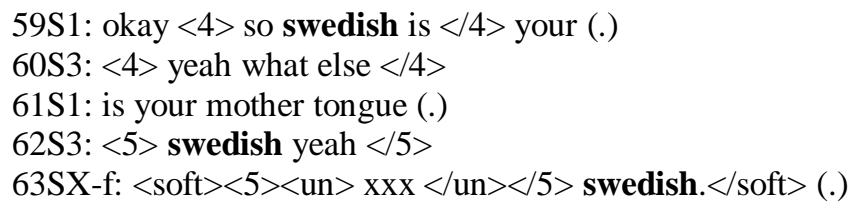

255S3: i have (.) a lot of (.) very generous friends (1) that('ve) (.) they ALways invite me and (1) yes

256S1: okay

257S3: and they're austrians (.)

258S1: <reading_aloud> sporty?</reading_aloud $>\{S 1$ reads from S3's notes $\}$

259S3: sporty

So in (45), the native language of Speaker 3 is confirmed through Repetition by her; and in (46), one stereotype that Austrians are sporty is confirmed. There is a lot of Intersubjectivity, also because of the discussion of stereotypes:

$$
\begin{aligned}
& \text { 438S1: erm (.) in what respect (.) beautiful? (.) like to be beautiful like to } \\
& \text { be: austrian:? like to be } \\
& \text { 439S6: yeah er i- in terms of outer appearance. }<4>\text { especially }</ 4> \\
& \text { 440S1: }<4>\text { outer appea }</ 4>\text { rance? }= \\
& \text { 441S6: }=\text { espec }<5>\text { ially }</ 5> \\
& \text { 442S1: }<5>\text { cloth }</ 5>\text { ing (you mean) } \\
& \text { 443S6: yeah }<8>\text { especially }</ 8>\text { in vienna. }
\end{aligned}
$$

The appearance of Austrians is discussed here, and speakers add information to specify what this refers to. 
Next, we have service encounter data:

\begin{tabular}{|c|c|c|c|c|c|}
\hline Text\# & InterSubj & Continuers & Correction & Repetition & Comment \\
\hline 421 & 26 & 0 & 1 & 3 & 8 \\
\hline 422 & 26 & 0 & 0 & 6 & 3 \\
\hline 423 & 27 & 0 & 0 & 13 & 5 \\
\hline 451 & 9 & 0 & 0 & 1 & 3 \\
\hline 452 & 44 & 0 & 1 & 8 & 1 \\
\hline Total (/183) & $\mathbf{1 3 0}$ & $\mathbf{0}$ & $\mathbf{2}$ & $\mathbf{3 1}$ & $\mathbf{2 0}$ \\
& $\mathbf{( 7 1 . 0 4 \% )}$ & $\mathbf{( 0 \% )}$ & $\mathbf{( 1 . 0 9 \% )}$ & $\mathbf{( 1 6 . 9 4 \% )}$ & $(\mathbf{1 0 . 9 3 \% )}$ \\
\hline
\end{tabular}

Table 5: Ellipsis in service encounters

Intersubjectivity is by far the most common, and there are no examples of Continuers. This is not unexpected as service encounters are very asymmetrical in their power relationships, and so encouragement is not to be expected, except on behalf on the person with greater power. As Garcia (2004) notes, service encounters are characterised by many questions, particularly from the students in these texts, which all contain advice sessions for new exchange students. Mauranen (2006) argues similarly that such encounters are transactional in nature, as people go in with the goal of obtaining information/services. Thus, they are similar to retail encounters. Repetition is particularly frequent in EDsve423. Details are repeated, and misunderstandings are corrected by repetition:

136S1: e:r (.) that's on the SECond sheet i gave you? (1) the: university of vienna is organizing an orientation for all erasmus students? (.) and there you get some general information about university? hh a:nd (.) the next free date for the orientation would be THIS friday? (.) from two to four $<$ spel $>$ p $\mathrm{m}$ ? $</$ spel $>$ (.) e:r (.) do you have time? (.)

137S4: yes (.) <soft $>$ (it's) $\langle 6\rangle\langle$ un $>\mathrm{xx}</$ un $\rangle</ 6\rangle</$ soft $\rangle$

138S1: $\langle 6\rangle$ is it okay? $\langle/ 6\rangle(2) \mathrm{erm}=$

139S2: $=\langle$ soft $>$ what is it? $</$ soft $>$

140S1: for the orientat $\langle 7>$ ion $\langle/ 7\rangle$

141S2: $\langle 7\rangle$ o: $\mathrm{h}\langle/ 7\rangle$ i see $=$

142S4: $=$ er fri- er THIS $()<8>$. friday? $</ 8>$ this $\langle 9\rangle$ fri $</ 9>$ day (4)

143S1: $\langle 8>$ this FRIday $</ 8>$

144S1: $\langle 9\rangle \mathrm{mhm}$ ? $</ 9\rangle$

145S2: $\langle 1>$ and what time? $</ 1>$

146S4: $<1>$ it's from $</ 1>$ two to four $<$ spel $>$ p m $</$ spel $>$ it's on the sheet i: gave you

147SX-5: <soft> on this sheet?</soft> (4)

148SX-2: two to FOUR . (.)

(49)

174S4: <to S2> where can we buy this ticket (.) in a station (.) (okay) $</$ to S2> 
175S2: <to S4> (.) pardon?</to S4>

176S4: <to S2> this TIcket. (1) when (.) WHERE can we buy it?</to S2>

The date and time of an orientation session is repeated in (48), while the question is (49) is repeated.

Finally, we turn to workshop discussion data:

\begin{tabular}{|c|c|c|c|c|c|}
\hline Text\# & InterSubj & Continuers & Correction & Repetition & Comment \\
\hline 9 & 17 & 2 & 1 & 4 & 3 \\
\hline 15 & 37 & 8 & 3 & 11 & 6 \\
\hline 242 & 28 & 3 & 4 & 12 & 5 \\
\hline 302 & 164 & 22 & 0 & 49 & 13 \\
\hline 303 & 27 & 9 & 0 & 11 & 5 \\
\hline 304 & 49 & 8 & 5 & 15 & 7 \\
\hline 306 & 32 & 18 & 1 & 9 & 2 \\
\hline 464 & 24 & 5 & 0 & 18 & 6 \\
\hline 499 & 37 & 14 & 1 & 11 & 6 \\
\hline 590 & 22 & 0 & 1 & 0 & 0 \\
\hline Total (/739) & $\mathbf{4 4 1}$ & $\mathbf{8 9}$ & $\mathbf{1 6}$ & $\mathbf{1 4 0}$ & $\mathbf{5 3}$ \\
& $\mathbf{( 5 9 . 6 8 \% )}$ & $\mathbf{( 1 2 . 0 4 \% )}$ & $\mathbf{( 2 . 1 7 \% )}$ & $\mathbf{( 1 8 . 9 4 \% )}$ & $\mathbf{( 7 . 1 7 \% )}$ \\
\hline
\end{tabular}

Table 6: Ellipsis in workshop discussions

After Intersubjectivity, Repetition comes somewhat ahead of Continuers. In EDwsd302, there are the most instances of all functions except Continuers. This is most likely due to the size of the text at 2400 lines, compared to the 1900 in EDwsd304 and 1600 in EDwsd306. Repetition is a big feature of EDwsd302 as students are explaining their core values for human life, and these are repeated by the instructor, and are commented on in the form of Continuers:

153S20: a:nd <fast> money </fast> and the most important <1> er freedom $\langle/ 1>$

154S18: $<1>$ what was $</ 1>$ that $=$

155S20: $=<$ fast $>$ money $</$ fast $>$ (1)

156S18: many?

157S20: yeah

158S18: or money

159S20: MONEY (.)

160S18: money all right. $=$

161S20: = money (.)

162S18: money?

163S20: yeah. no- <un> $x</ u n>$ not for me but e:r for e:r (1) for $\mathrm{i}$ think about er

rich rich people not e:r not e:r (2) e:r yeah. money. yes 
190S4: well <1> i (.) i i i don't </1> say that this value is better than <2> another one so $</ 2>$

191S18: $\langle 1\rangle\langle$ un $>\mathrm{xx}</$ un $>$ more general ones or $</ 1>$

192S18: $\langle 2>$ no definitely $</ 2>$ not. $<8>$ but $</ 8>$

193S4: $<8>$ so $</ 8>$ just if if you have very different values yeah (.) somehow you have to find a solution so take t- two of yours and two of yours and negotiate about another one $=$

194S18:=@@@ $@ 9\rangle$ all right $\langle/ 9\rangle$

195S20: $\langle 9\rangle$ okay $\langle/ 9\rangle\langle 3\rangle$ okay $\langle/ 3\rangle$

196S4: $\langle 3\rangle$ something $</ 3>$ like that $=$

197S18: $=($ great $)=$

198S20: $=$ okay $=$

In (50), money as one value is introduced and repeated, and in (51) Speaker 4's contribution is commented on. There are also many Continuers in EDwsd306 because students are presenting scenarios for what will happen to languages in Europe:

46S8: but then $<8>$ again the extreme $</ 8>$ (.)

47SS: <8>@@@@@</8>

48S8: of number (.) three: (.) is also (.) just as bad because that would be total chaos and nobody will understand each other (.)

49S6: okay (.) $\{$ S6 starts writing on blackboard $\}$

50S8: erm (1) (so it's) <un> xx </un> (too) @ @ (.) <9> er (it's it's) <un> $\mathrm{xxx}</ \mathrm{un}\rangle\langle/ 9\rangle$

51S6: $\langle 9\rangle\langle$ un $>\times \times \times \times</$ un $>$ TWO $</ 9>$ worst case (.)

52S8: yeah because (.) <un > x x x x </un> two extremes

53S6: okay

54S8: so =

55S6: $=$ perfect $(1)$

Here, the contribution of Speaker 8 is commented on.

Now, we will compare the data in all speech event types:

\begin{tabular}{|c|c|c|c|c|c|}
\hline Speech Ev & InterSubj & Continuers & Correction & Repetition & Comment \\
\hline Conversation & 227 & 29 & 1 & 32 & 46 \\
\hline Interview & 148 & 17 & 2 & 35 & 26 \\
\hline $\begin{array}{c}\text { Working group } \\
\text { discussion }\end{array}$ & 153 & 47 & 1 & 48 & 31 \\
\hline Seminar discussion & 155 & 75 & 9 & 75 & 25 \\
\hline Service encounter & 130 & 0 & 2 & 31 & 20 \\
\hline $\begin{array}{c}\text { Workshop } \\
\text { discussion }\end{array}$ & 441 & 89 & 16 & 140 & 53 \\
\hline Total (/2104) & $\begin{array}{c}\mathbf{1 2 5 4} \\
\mathbf{( 5 9 . 6 0 \% )}\end{array}$ & $\begin{array}{c}\mathbf{2 5 7} \\
(\mathbf{1 2 . 2 1 \%})\end{array}$ & $\begin{array}{c}\mathbf{3 1} \\
(\mathbf{1 . 4 7 \%})\end{array}$ & $\begin{array}{c}\mathbf{3 6 1} \\
(\mathbf{1 7 . 1 6 \% )})\end{array}$ & $\begin{array}{c}\mathbf{2 0 1} \\
\mathbf{( 9 . 5 5 \% )}\end{array}$ \\
\hline
\end{tabular}

Table 7: Ellipsis in all speech events 
The combined results show that just under $60 \%$ of examples of ellipsis carry the Intersubjectivity function. Then, a further $30 \%$ of cases carry either the Repetition or Continuer functions. Repetitions come so high because of the contribution from workshop discussions (140 out of 361 instances). We can expect the other results, as Intersubjectives develop discourse, while Continuers and Comments provide feedback. Thus, we can conclude our analysis by saying that participants are clearly being interactive in many different ways in this data.

\section{Conclusions}

Our study of the VOICE corpus has demonstrated that ellipsis is a strong marker of interaction in oral discourse. Many different instances of each function were found, particularly Intersubjectivity. There were many variations in what was found, but they were argued to be consequences of the particular features of the relevant texts. For example, the amount of Repetitions was argued to be related to the text dealing with a questionnaire or a discussion of a presentation, and so certain points were likely to be repeated by speakers. The speech event was important too, since we saw that there were very few Continuers in events with asymmetrical power relationships like interviews. Further work on different sources of oral discourse is naturally needed to support or modify these conclusions, and a comparison between this and written data would also be valuable to see if the trends found in VOICE are particular to the texts themselves, or to oral discourse in general.

\section{References}

Chun, Dorothy M. 1994. Using computer networking to facilitate the acquisition of interactive competence. System 22, 1: 17-31.

Cogo, Alessia and Martin Dewey. 2012. Analysing English as a lingua franca: A corpus-driven investigation. London/New York: Continuum International Publishing Group.

Cogo, Alessia. 2009. Accommodating difference in EFL conversations: A study of pragmatic strategies. In A. Mauranen and E. Ranta (eds.). English as a lingua franca: Studies and findings. Newcastle: Cambridge Scholars Publishing: 254-273.

Corver, Norbert. 1990. The syntax of left branch extractions. PhD thesis, Katholieke Universiteit, Brabant.

van Craenenbroeck, Jeroen. 2010. The syntax of ellipsis: Evidence from Dutch dialects. New York: Oxford University Press.

Darhower, Mark. 2002. Interactional features of synchronous computer-mediated communication in the intermediate L2 class: A sociocultural case study. Calico, 19, 2: 249-277.

Fernández-García, Marisol and Asuncion Martínez Arbelaiz. 2003. Learners' interactions: A comparison of oral and computer-assisted written conversations. $\operatorname{ReCALL}, 15,1: 113-136$. 
Garcia, Paula. 2004. Meaning in academic contexts: A corpus-based study of pragmatic utterances. PhD thesis: Northern Arizona University.

Heritage, John. 2005. Conversation analysis and institutional talk. In K. Fitch and R. Sanders (eds.). Handbook on language and social interaction. Mahwah, New Jersey: Lawrence Erlbaum Associates: 103-147.

Holly, Werner. 1995. Secondary orality in the electronic media. In U. Quasthoff (ed.). Aspects of oral communication. Berlin: Walter de Gruyter: 340-363.

Kramsch, Claire. 1983. Interaction in the classroom: Learning to negotiate roles and meanings. Die Unterrichtspraxis 16, 2: 175-190.

Lave, Jean and Etienne Wenger. 1991. Situated learning: Legitimate peripheral participation. Cambridge, U.K.: Cambridge University Press.

Lobeck, Anne. 1995. Ellipsis: Functional heads, licensing and identification. New York: Oxford University Press.

Mauranen, Anna. 2006. Signalling and preventing misunderstanding in English as a lingua franca communication. International Journal of the Sociology of Language 177: $123-150$.

Mauranen, Anna. 2012. Exploring ELF: Academic English shaped by non-native speakers. Cambridge, U.K.: Cambridge University Press.

Merchant, Jason. 2001. The syntax of silence. Oxford, England: Oxford University Press.

Merchant, Jason. 2004. Fragments and ellipsis. Linguistics and Philosophy, 27: 661-738.

Merchant, Jason. 2007. Three kinds of ellipsis: Syntactic, semantic and pragmatic? Available from: http://ling.auf.net/lingBuzz/000536.

Morita, Naoko. 2004. Participation and identity in second language academic communities. TESOL Quarterly 38, 4: 573-603.

Oh, Sun-Young. 2005. English zero anaphora as an interactional resource. Research on Language and Social Interaction 38, 3: 267-302.

Oh, Sun-Young. 2006. English zero anaphora as an interactional resource II. Discourse Studies 8: 817-846.

Peterson, Mark. 2009. Learner interaction in synchronous CMC: A sociocultural perspective. Computer-Assisted Language Learning, 22, 4: 303-321.

Pölzl, Ulrike and Barbara Seidlhofer. 2006. In and on their own terms: the "habitat factor" in English as a lingua franca interactions. International Journal of the Sociology of Language 177: 151-176.

Ross, John Robert. 1967. Constraints on variables in syntax. PhD thesis, MIT.

Scollon, Ron and Suzanne Scollon. 1995. Somatic communication: How useful is 'Orality' for the characterization of speech events and cultures? In U. Quasthoff (ed.). Aspects of oral communication. Berlin: Walter de Gruyter: 19-29.

Scott, Kate. 2013. Pragmatically motivated null subjects in English: A relevance theory perspective. Journal of Pragmatics 53: 68-83. http://dx.doi.org/10.1016/j.pragma.2013.04.001

Stainton, Robert. 2006. Words and thoughts: Subsentences, ellipsis and the philosophy of language. Oxford, England: Clarendon.

Suviniitty, Jaana. 2012. Lectures in English as a lingua franca: Interactional features. PhD thesis: University of Helsinki. 
VOICE. 2011. The Vienna-Oxford International Corpus of English (version 1.1 Online). Director: B. Seidlhofer; Researchers: A. Breiteneder, T. Klimpfinger, S. Majewski, R. Osimk, M.-L. Pitzl. http://voice.univie.ac.at. (date of last access, 1 March 2013).

Wenger, Etienne. 1998 Communities of Practice: Learning, Meaning and Identity. Cambridge: Cambridge University Press.

White, Jonathan. 2011. Reduced forms in chat discourse. In A. Ylikiiskilä and M. Westman (eds), Language for the Future: Papers from the ASLA Symposium in Falun 12-13 November, 2010: 231-247.

White, Jonathan. 2013. Language economy in computer-mediated communication: Learner autonomy in a community of practice. In B. Zou, M. Xing, C. Xiang, Y. Wang, M. Sun (eds.). Computer-assisted foreign language teaching and learning: Technological advances. Hershey, Pa.: IGI Global: 73-89.

\begin{abstract}
About the author
Jonathan White is a senior lecturer in English Linguistics at Högskolan Dalarna in Sweden. He does research on computer-mediated communication and pragmatics, linked to the notion of communities of practice. His focus is on language economisation and how it is a marker of discourse community formation. He is also doing research on different forms of oral communication.
\end{abstract}

